\title{
Bone marrow adipose amount influences vertebral bone strength
}

\author{
MO ZHU ${ }^{1 *}$, GUANGYU HAO ${ }^{1 *}$, JIANMING XING $^{1}, \mathrm{SU} \mathrm{HU}^{1}$, DECHUN GENG $^{2}$, \\ WEN ZHANG $^{2}$, QIANQIAN WANG ${ }^{1}$, CHUNHONG HU $^{1}$ and XIMING WANG ${ }^{1}$ \\ Departments of ${ }^{1}$ Radiology and ${ }^{2}$ Orthopedic, The First Affiliated Hospital of Soochow University, \\ Suzhou, Jiangsu 215006, P.R. China
}

Received June 4, 2018; Accepted November 8, 2018

DOI: $10.3892 /$ etm.2018.7003

\begin{abstract}
Association of bone marrow adipose and microstructure with bone strength in osteoporotic rats using MR Dixon analysis and micro-CT was evaluated. A total of 40 female Sprague-Dawley rats (6-month-old) were divided randomly into sham-operated (SHAM, n=20) group and ovariectomized (OVX, n=20) group. Fat fraction $(F F)$ was measured by two-point Dixon method with MR imaging at the baseline, 4th, 8th and 12th week, respectively. After sacrifice by anesthesia, the fifth lumbar vertebrae bone was sampled for micro-CT scanning. The biomechanical analysis was also performed. FF in osteoporotic rats significantly increases with time, which correlates with bone microstructure parameters. Compared with biomechanical test, FF showed negative correlation with break stress and elastic modulus. It also suggested that loss of bone mass was accompanied with the increase of adipose tissue content in vertebrae bone marrow. The impairment of bone strength leads to the risk of brittle fracture. In conclusion, the bone marrow adipose amount obtained by MR Dixon and microstructure by micro-CT correlates to bone strength in osteoporotic rats.
\end{abstract}

\section{Introduction}

Osteoporosis (OP) is a chronic and systematic disease characterized by reduced bone mass and destruction of bone microstructure (1). In the early stage, although the risk of brittle fractures increase significantly, there is no or little clinical manifestations arousing patient's due attention. The present diagnostic standard, bone mineral density (BMD), can not fully reflect the changes in bone strengths. In fact, for

Correspondence to: Dr Chunhong $\mathrm{Hu}$ or Dr Ximing Wang, Department of Radiology, The First Affiliated Hospital of Soochow University, 188 Shizi Road, Suzhou, Jiangsu 215006, P.R. China

E-mail: sdhuchunhong@sina.com

E-mail: wangximing@163.com

\section{${ }^{*}$ Contributed equally}

Key words: osteoporosis, two-point Dixon, micro-CT, biomechanical analysis
BMD standard, patients with fragile fractures were frequently diagnosed above the OP threshold (2). Recent studies showed that the reduction of bone strength is often accompanied by an increase amount of bone marrow adipose tissues and decreased bone mass in post-menopausal OP patients (3). Furthermore, change of bone microstructure parameters was observed as well (4). MRI-based detection of bone marrow adipose tissue was limited to human bone or rabbit models and the combined application of micro-CT and mechanical experiments in OP studies are rare. We hypothesize that adipose tissue contents and bone microstructure correlate with each other and both influence bone strength during the process of OP. This study analyzed the vertebral bone marrow adipose tissue contents and bone microstructure changes in OP rats longitudinally with these two techniques.

\section{Materials and methods}

Forty Sprague-Dawley (SD) female rats (6-month-old) without history of pregnancy were used in this study. The rats were SPF grade and weighed approximately $205 \pm 20 \mathrm{~g}$, and were purchased from Shanghai Slack Laboratory Animal Co., under the license of SCXK (Shanghai, China) 2012-0002. The animals were randomly divided into SHAM (20 rats) and OVX group (20 rats). The experimental treatments were in accordance with the guidelines of Ethical Issues in Animal Experimentation, 2009 (Table I). This study was approved by the Animal Ethics Committee of Soochow University Animal Center (Suzhou, China).

\section{Methods}

Castration and SHAM. Forty healthy female Sprague-Dawley rats (6-month-old) were randomly divided into ovariectomized group (OVX, 20 rats) and sham operation group (SHAM, 20 rats). Anesthesia was performed by intraperitoneal injection with $10 \%$ chloral hydrate. The OVX group rats were subjected to bilateral ligation and removal of ovaries, while from SHAM group rats with retained ovaries the same quantity of retroperitoneal fat was resected. To prevent surgical infection, penicillin was used routinely. All the rats were subjected to sub-cage feeding, free drinking, eating and free activities.

Dixon water-fat separation imaging. Prior to MRI dedicated sequences, conventional T1WI and T2WI sequential scan was performed to exclude possible vertebral lesions. MRI 
examinations were conducted at baseline, 4th, 8th, and 12th weeks after surgery in each five rats from the two groups with the human knee coil. The Dixon scan used the TSE-Dixon technique with the same parameters $(\mathrm{TR}=2,800.00 \mathrm{msec}$, $\mathrm{TE}=96.00 \mathrm{msec}, \mathrm{FOV}=105 \times 105 \mathrm{~mm}$, layer thickness $=2.0 \mathrm{~mm}$, spacing $=2.0 \mathrm{~mm}, 192 \times 56$, inversion angle $=150^{\circ}$, bandwidth $=349 \mathrm{~Hz} /$ pixel, pixel $=0.2 \times 0.2 \times 2.0 \mathrm{~mm}$, excitation for 3 times and scanning time $6 \mathrm{~min}$ ). Four dataset images with the synchronized, opposite, fat and water phase were obtained. The fat phase was divided by the synchronized phase image to generate a DIV (divided, DIV) image with workstation software. By combining the generated DIV image and the water phase image as the position one, a hand-drawn region of interest (ROI) was made to estimate the fat fraction (FF), i.e. the percentage of fat intensity in the total signal of water-fat mixture. The calculation formula is FF $=$ Sfat $/($ Sfat + Swater $) \times 100 \%$ (Sfat and Swater represents the total signal intensity of aimed pixel values, individually), marrow FF of the interest region was obtained for each time-point. Each measurement was performed twice by the same investigator and the average value was considered as the final result. Additionally, interested areas containing the maximum inclusion of the entire cancellous bone in the 5th lumbar vertebra were measured, carefully avoiding the surrounding cortex of bones.

Micro-CT scan. After the MRI examination, the rats were sacrificed in a $\mathrm{CO} 2$ chamber and the specimens were sampled for micro-CT scanning. The scanning parameters were as follows: Voltage $50 \mathrm{KV}$, current $200 \mathrm{~mA}$, interlayer spacing $18 \mu \mathrm{m}$, scanning rotation $180^{\circ}$, scanning time $10 \mathrm{~min}$, average frame rate 1 , angle gains $0.7^{\circ}$ and the exposure time $400 \mathrm{msec}$. CT values were calibrated with the standard phantom before scanning. Data were imported into workstation and were analyzed with in-house CT analyzer (version 1.10) software. In order to intuitively display the morphological characteristics of each sample, three-dimensional reconstruction was performed by using Mimics 10.01 .

Biomechanical analysis. Samples were thawed under room temperature and were placed on testing machine. By adjusting the pressure head, close to the lumbar vertebral body, the span was set at $1 \mathrm{~cm}$ and specimens were made with a speed of $1 \mathrm{~mm} / \mathrm{min}$ movement. The compression was stopped when the vertebral bodies had a fracture or collapse. The load/deformation curve was automatically depicted with the workstation's in-house drawing software. In this experiment, the tested indicators were as follows: Maximum breaking load, failure stress and elastic modulus.

Statistical analysis. All the experimental data are presented as mean \pm standard deviation (SD) and analyzed with t-test by SPSS 17.0 (SPSS, Inc., Chicago, IL, USA). P<0.05 was considered to indicate a statistically significant difference.

\section{Results}

Time-course FF variation in MR Dixion. Compared with SHAM group, FF increased with time in the OVX group by $20.8,42.1$ and $62.4 \%$ at 4 th, 8 th and 12 th week, respectively. At the 4 th, 8 th and 12 th week, the FF increased by 18.8, 36.0 and
Table I. Based on the two-point Dixon water-fat separation, vertebral bone marrow adipose tissue was analyzed in osteoporotic rats. The relevant materials and instruments are listed.

\begin{tabular}{ll}
\hline Materials and instruments & \multicolumn{1}{c}{ Vendors } \\
\hline Micro-CT Skyscan1176 & Skyscan, Kontich, Belgium \\
CT analyzer1.10 & Skyscan \\
Mimics10.01 & Skyscan \\
Magnetom Skyra 3T & Siemens AG, Munich, Germany \\
HY-1080 & Hengyi Precision Instrument Co. Ltd., \\
PFA & Shanghai, China \\
& Wuxi Zhanwang Chemical Co., Ltd., \\
& Wuxi, China \\
\hline
\end{tabular}

$42.4 \%$ respectively, when comparing with those in the SHAM group. Overall, the trend was statistically significant from the 4th week (Fig. 1; Table II).

Bone morphological analysis through micro-CT. In OVX group, BVF showed a time-course decreasing trend, whereas Tb.Sp and SMI demonstrated an increasing trend. Specifically, Tb.Sp differences between the OVX group and SHAM group occurred at the 4th week, while BVF and SMI occurred at the 8 th week. Tb.N did not show significant inter-group or intra-group differences. Moreover, Tb.Th reduced by $19.7 \%$ at the 12 th week compared with baseline and by $17.9 \%$ compared with SHAM group at the same timepoint (Table II). Three-dimensional reconstruction showed that the trabecular spaces followed a significant enlargement over time. Furthermore, the trabecular bones were partially broken, perforated and the bone mass significantly reduced (Fig. 2).

Biomechanical characteristics. Compared to SHAM group, the OVX group showed inferior maximum breaking load, breaking stress and elastic modulus. In the temporal analysis for OVX rats, there was a statistical difference of elastic modulus at the 4 th week from baseline, whereas the maximum failure load and failure stress showed statistical difference at the 8 th week (Table III).

Bone marrow histology. HE staining showed that the density and diameter of adipocytes tended to increase gradually with time in the OVX group (Fig. 3).

Relationship between FF, morphological parameters and biomechanical characteristics. FF was correlated with bone morphological parameters and biomechanical properties in OVX group. Specifically, FF was negatively associated with BVF $(\mathrm{r}=-0.879, \mathrm{P}<0.01)$, failure stress $(\mathrm{r}=-0.833, \mathrm{P}<0.01)$ and elastic modulus $(\mathrm{r}=-0.804, \mathrm{P}<0.01)$, whereas moderately related to maximum failure load $(\mathrm{r}=-0.716, \mathrm{P}<0.01)$ and $\mathrm{Tb}$.Th $(\mathrm{r}=-0.484, \mathrm{P}<0.05)$. FF was positively correlated with Tb.Sp $(\mathrm{r}=0.841, \mathrm{P}<0.01)$ and SMI $(\mathrm{r}=0.838, \mathrm{P}<0.01)$. However, there was no significant correlation between FF and Tb. N ( $\mathrm{r}=-0.198$, $\mathrm{P}>0.05)$. 
A

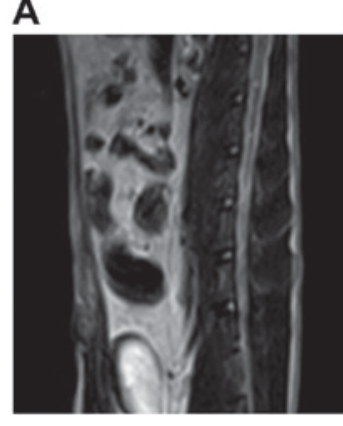

D

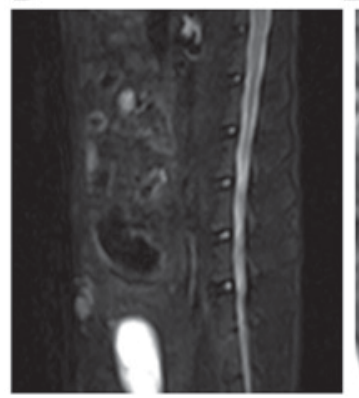

B

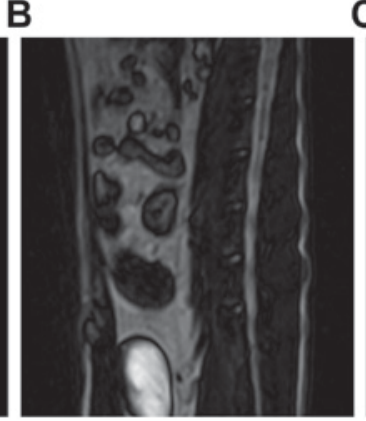

E

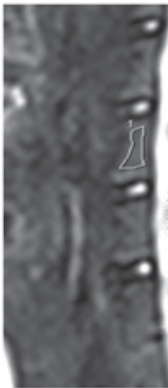

C

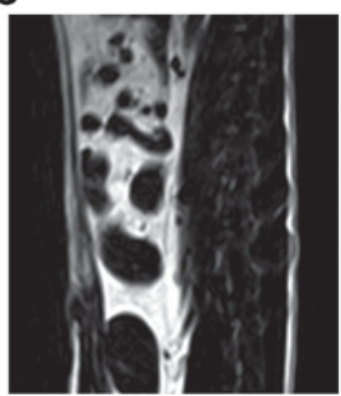

F

Figure 1. Images of two-point TSE-Dixon MRI of group OVX. (A-D) The TSE-Dixon image of the synchronized phase, the opposite phase, the lipid phase and the aqueous phase. (E-F) The schematic diagram of ROI FF by combining the DIV image (E) and water phase image (F). FF, fat fraction; ROI, region of interest.

Table II. Time-course profiling of FF and bone morphology.

\begin{tabular}{|c|c|c|c|c|c|c|c|}
\hline Items & Groups & Week 0 & Week 4 & Week 8 & Week 12 & F-value & P-value \\
\hline $\mathrm{FF}, \%$ & $\begin{array}{l}\text { SHAM } \\
\text { OVX }\end{array}$ & $\begin{array}{l}17.9 \pm 2.3 \\
17.8 \pm 1.4\end{array}$ & $\begin{array}{l}18.1 \pm 1.9 \\
21.5 \pm 1.8^{\mathrm{a}, \mathrm{d}}\end{array}$ & $\begin{array}{l}18.6 \pm 1.5 \\
25.3 \pm 1.6^{\mathrm{a}, \mathrm{b}, \mathrm{d}}\end{array}$ & $\begin{array}{l}20.3 \pm 1.7 \\
28.9 \pm 1.7^{\mathrm{a}-\mathrm{d}}\end{array}$ & $\begin{array}{r}1.739 \\
42.466\end{array}$ & $\begin{array}{r}0.199 \\
<0.001\end{array}$ \\
\hline BVF, $\%$ & $\begin{array}{l}\text { SHAM } \\
\text { OVX }\end{array}$ & $\begin{array}{l}56.43 \pm 2.22 \\
55.57 \pm 2.87\end{array}$ & $\begin{array}{l}56.35 \pm 2.64 \\
48.93 \pm 3.47^{a}\end{array}$ & $\begin{array}{l}55.12 \pm 3.65 \\
39.42 \pm 3.32^{\mathrm{a}, \mathrm{b}, \mathrm{d}}\end{array}$ & $\begin{array}{l}53.49 \pm 3.28 \\
31.41 \pm 2.98^{\mathrm{a}-\mathrm{d}}\end{array}$ & $\begin{array}{r}1.050 \\
55.903\end{array}$ & $\begin{array}{r}0.397 \\
<0.001\end{array}$ \\
\hline Tb.N, $\mathrm{mm}^{-1}$ & $\begin{array}{l}\text { SHAM } \\
\text { OVX }\end{array}$ & $\begin{array}{l}4.82 \pm 0.33 \\
4.78 \pm 0.26\end{array}$ & $\begin{array}{l}4.71 \pm 0.27 \\
4.67 \pm 0.31\end{array}$ & $\begin{array}{l}4.65 \pm 0.29 \\
4.73 \pm 0.27\end{array}$ & $\begin{array}{l}4.56 \pm 0.37 \\
4.51 \pm 0.36\end{array}$ & $\begin{array}{l}0.604 \\
0.789\end{array}$ & $\begin{array}{l}0.622 \\
0.517\end{array}$ \\
\hline $\mathrm{Tb} . \mathrm{Th}, \mu \mathrm{m}$ & $\begin{array}{l}\text { SHAM } \\
\text { OVX }\end{array}$ & $\begin{array}{l}119.73 \pm 9.99 \\
120.10 \pm 12.83\end{array}$ & $\begin{array}{l}119.62 \pm 10.12 \\
113.38 \pm 10.53\end{array}$ & $\begin{array}{l}118.24 \pm 13.50 \\
107.32 \pm 12.10\end{array}$ & $\begin{array}{c}117.50 \pm 13.98 \\
96.45 \pm 11.21^{\mathrm{a}, \mathrm{b}, \mathrm{d}}\end{array}$ & $\begin{array}{l}0.041 \\
3.683\end{array}$ & $\begin{array}{l}0.989 \\
0.034\end{array}$ \\
\hline $\mathrm{Tb} . \mathrm{Sp}, \mathrm{mm}$ & $\begin{array}{l}\text { SHAM } \\
\text { OVX }\end{array}$ & $\begin{array}{l}92.53 \pm 14.73 \\
91.39 \pm 13.10\end{array}$ & $\begin{array}{c}93.12 \pm 10.08 \\
117.92 \pm 8.41^{\mathrm{a}, \mathrm{d}}\end{array}$ & $\begin{array}{c}93.08 \pm 8.85 \\
133.41 \pm 14.90^{\mathrm{a}, \mathrm{d}}\end{array}$ & $\begin{array}{c}95.12 \pm 8.14 \\
159.47 \pm 10.75^{\mathrm{a}-\mathrm{d}}\end{array}$ & $\begin{array}{r}0.056 \\
28.015\end{array}$ & $\begin{array}{r}0.982 \\
<0.001\end{array}$ \\
\hline SMI & $\begin{array}{l}\text { SHAM } \\
\text { OVX }\end{array}$ & $\begin{array}{l}0.59 \pm 0.08 \\
0.53 \pm 0.09\end{array}$ & $\begin{array}{l}0.61 \pm 0.16 \\
0.74 \pm 0.13^{\mathrm{a}}\end{array}$ & $\begin{array}{l}0.65 \pm 0.12 \\
1.09 \pm 0.19^{\mathrm{a}, \mathrm{b}, \mathrm{d}}\end{array}$ & $\begin{array}{l}0.67 \pm 0.15 \\
1.42 \pm 0.17^{\text {a-d }}\end{array}$ & $\begin{array}{r}0.367 \\
34.150\end{array}$ & $\begin{array}{r}0.778 \\
<0.001\end{array}$ \\
\hline
\end{tabular}

${ }^{\mathrm{a}} \mathrm{P}<0.05$, statistical difference compared to week 0 ; ${ }^{\mathrm{b}}<0.05$, statistical difference compared to week 4 ; ${ }^{\mathrm{c}} \mathrm{P}<0.05$, statistical difference compared to week $8 ;{ }^{\mathrm{d}} \mathrm{P}<0.05$, statistical difference between the OVX group and the SHAM group; FF, fat fraction.

Table III. Time-course profiling of biomechanical characteristics after ovariectomized treatment.

\begin{tabular}{|c|c|c|c|c|c|c|c|}
\hline Items & Groups & Week 0 & Week 4 & Week 8 & Week 12 & F-value & P-value \\
\hline Break load, $\mathrm{N}$ & $\begin{array}{l}\text { SHAM } \\
\text { OVX }\end{array}$ & $\begin{array}{l}215.3 \pm 26.8 \\
209.7 \pm 26.2\end{array}$ & $\begin{array}{l}207.3 \pm 29.3 \\
182.3 \pm 28.4\end{array}$ & $\begin{array}{l}201.8 \pm 31.1 \\
150.3 \pm 33.0^{\mathrm{a}, \mathrm{d}}\end{array}$ & $\begin{array}{l}194.7 \pm 32.8 \\
110.3 \pm 45.3^{\mathrm{a}, \mathrm{b}, \mathrm{d}}\end{array}$ & $\begin{array}{l}0.419 \\
7.899\end{array}$ & $\begin{array}{l}0.742 \\
0.002\end{array}$ \\
\hline Break stress, $\mathrm{MPa}$ & $\begin{array}{l}\text { SHAM } \\
\text { OVX }\end{array}$ & $\begin{array}{l}23.3 \pm 2.9 \\
22.6 \pm 2.5\end{array}$ & $\begin{array}{l}22.3 \pm 3.8 \\
19.7 \pm 3.0\end{array}$ & $\begin{array}{l}21.6 \pm 3.6 \\
16.1 \pm 2.5^{\mathrm{a}, \mathrm{d}}\end{array}$ & $\begin{array}{l}20.8 \pm 3.5 \\
11.9 \pm 3.2^{\mathrm{a}-\mathrm{d}}\end{array}$ & $\begin{array}{r}0.465 \\
13.760\end{array}$ & $\begin{array}{r}0.711 \\
<0.001\end{array}$ \\
\hline Elastic modulus, $\mathrm{MPa}$ & $\begin{array}{l}\text { SHAM } \\
\text { OVX }\end{array}$ & $\begin{array}{l}476.2 \pm 25.1 \\
482.4 \pm 25.7\end{array}$ & $\begin{array}{l}480.8 \pm 39.3 \\
364.8 \pm 45.6^{\mathrm{a}, \mathrm{d}}\end{array}$ & $\begin{array}{l}532.4 \pm 29.8^{\mathrm{a}, \mathrm{b}} \\
291.4 \pm 35.0^{\mathrm{a}, \mathrm{b}, \mathrm{d}}\end{array}$ & $\begin{array}{l}551.3 \pm 30.0^{\mathrm{a}, \mathrm{b}} \\
263.9 \pm 43.2^{\mathrm{a}, \mathrm{b}, \mathrm{d}}\end{array}$ & $\begin{array}{r}7.076 \\
32.771\end{array}$ & $\begin{array}{r}0.003 \\
<0.001\end{array}$ \\
\hline
\end{tabular}

${ }^{\mathrm{a}} \mathrm{P}<0.05$, statistical difference compared to week 0 ; ${ }^{\mathrm{b}} \mathrm{P}<0.05$, statistical difference compared to week 4 ; ${ }^{\mathrm{c}} \mathrm{P}<0.05$, statistical difference compared to week $8 ;{ }^{d} \mathrm{P}<0.05$, statistical difference between the OVX group and the SHAM group. 
A

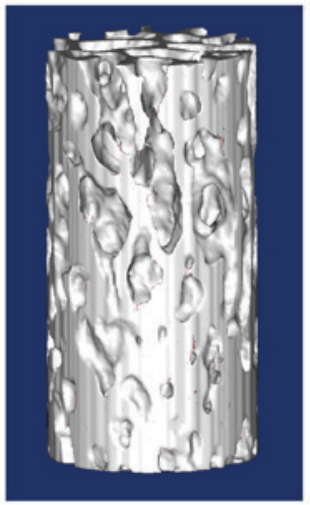

B

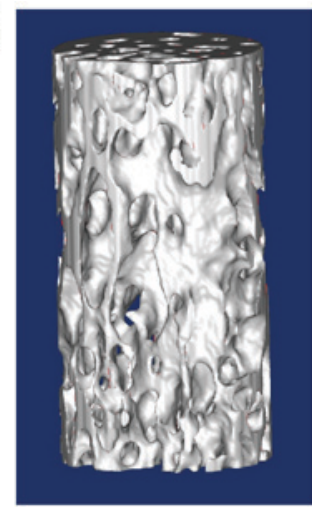

C

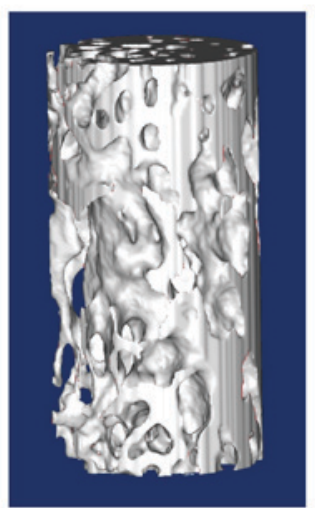

D

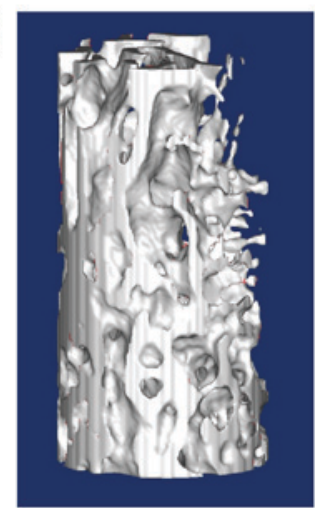

Figure 2. Three-dimensional reconstruction of vertebral bone through micro-CT for OVX group rats. (A-D) Represents the morphological reconstruction of vertebral bone at baseline, 4th, 8th and 12th weeks in OVX group rats. After 12 weeks, the trabecular gaps significantly expanded, trabecular fracture and perforation was also remarkably increased.
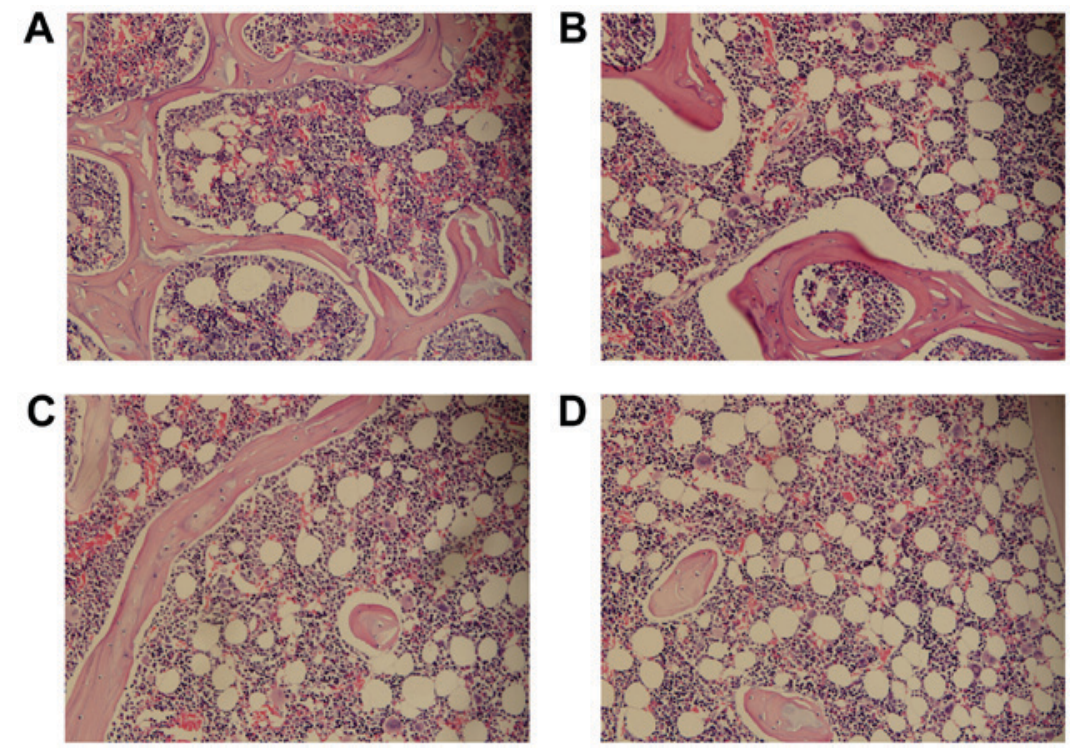

Figure 3. HE staining of OVX group. (A-D) The baseline, the 4th week, the 8th week and the 12th week HE image (HE; magnification, x200).

\section{Discussion}

Currently, BMD is widely used as the 'gold standard' for OP diagnosis. However, due to its low sensitivity and poor specificity, BMD cannot fully reflect the actual changes of bone strength. Previous studies showed that there was a great 'overlap' of BMD between patients with or without brittle fractures (5). It is now believed that the changes of bone mass and bone marrow components are the authentic determinant factors of bone fragility, thus, could play as more accurate diagnostic roles independent of BMD (6-8).

By using X-ray scanning and three-dimensional reconstruction technology, micro-CT techniques abolish the limitations of plane projection. Therefore, thickness of various 
forms of bone structure can be directly measured which clearly describes the three-dimensional distribution and bone morphological characteristics. Moreover, as the ideal tools for bone morphology study, micro-CT techniques can effectively monitor the dynamic changes of cancellous bone trabecula (9). Due to reduced level of estrogen through bilateral ovarian castration, bone morphological characteristics of vertebral bodies notably changed as shown by the two-point Dixon combined with micro-CT analysis. After 8 weeks of castration, bone microstructure parameters, except Tb.N and Tb.Th, significantly changed, which was in accordance with previous studies (10). At 4th week, the BVF decreased by $11.9 \%$, whereas the Tb.Sp and SMI increased by 29.0 and 39.6\%, respectively in the OVX group. These changes were preceding other parameters. At 12th week, Tb.Th decreased by $19.7 \%$ while Tb.N showed a decreasing trend though without statistically significance. The changed levels of Tb.N and Tb.Th could be ascribed to the redistribution of stress point in cancellous bone trabeculae, which were caused by the degeneration of bone microarchitecture as well as losses of bone mass. Therefore, reconstruction of the bone trabeculae could delay the reduced level of Tb.N and Tb.Th. There is a certain correlation between trabecular bone microstructure parameters and the biomechanical test results, such as breaking stress, elastic modulus and the maximum breaking load. In this study, BVF, Tb.Sp and SMI showed the closest relationship to mechanical properties and could be used as effective predictors of fracture risk. Furthermore, the cancellous bone trabeculae thinning, absorption, fracture and even perforation could limit the resistance to normal tensions in OP. Minematsu et al (11) also verified that the bone morphological parameters were closely related to the mechanical strength of OP bone tissue. In our previous studies, the two-point Dixon water-fat separation technique was proved as a noninvasive monitoring method for changes of bone marrow adipose tissue content in OP process. The changed level of bone marrow adipose tissue was found prior to bone mass lost, that was consistent with the findings of Di Iorgi et al (12). Additionally, the bone marrow fat content and the morphological parameters showed certain correlation with the biomechanical properties. There was a positive relationship between bone marrow fat content and Tb.Sp/SMI, whereas BVF was negatively correlated. In terms of bone strength, there was a significant negative correlation between FF and the failure stress and elastic modulus, indicating that the increased level of bone marrow adipose tissue could weaken the bone strength and increases the risk of brittle fracture in OP induced by estrogen deficiency. In another case, it showed that bone marrow adipose tissue played an important role in OP development (13). Previous studies showed that OP patients were considerably accompanied by an increasing level of bone marrow adipose contents, while alleviated OP lead to decreasing adipose level. Interestingly, diabetes and glucocorticoid-treated patients showed a negative correlation with the level of bone mass, which lead to the speculation that the bone marrow adipose tissue plays a negative role in controlling bone formation (14). Here, bone marrow adipose content, morphological parameters and biomechanical properties was verified to be closely associated. At present, mechanisms of increased bone marrow adipose tissue affecting bone strength are still unclear. Typical explanations are as follows: One theory goes that increased level of bone marrow adipose tissue was a compensatory results of trabecular bone thinning in the cancellous bone and the spaces caused by the trabecular gap enlargement (15), while a contrary opinion argues that the increased level of bone marrow adipose tissue was not a 'passive' process, but could 'actively' compress the trabecular bone and accelerates the destructive absorption of cancellous bone (4). Another theory considering the bone marrow in the marrow cavity, in addition to undertaking hematopoietic functions, play roles in mechanical support and pressure buffering. It is reasonable to note that yellow bone marrow bears good compressibility and shows significant weakness of structural support functioning compared to red bone marrow. Therefore, growth of yellow bone marrow could gradually replace the red bone marrow, which leads to a weakened bone strength after years of aging (16). The third theory accounts the fact that osteoblasts and adipocytes in bone marrow both derive from mesenchymal stem cells (MSCs) $(17,18)$. Over-differentiation of adipocytes could inevitably cause poor osteogenics, which lead to an interesting assumption that migration of MSCs into adipogenic cells could be the origin of OP (19). Specifically, OP occurs through regulating the expression of peroxisome proliferation-activated receptor (PPAR $\gamma$ ) and core-binding factor $\alpha 1$ /runt-related transcription factor 2 (Cbf $\alpha 1 /$ Runx2) (20).

In conclusion, increased level of adipose tissue in the bone marrow weakens the bone strength and increases the risk of fragile fractures in OP.FF and bone morphological parameters, being interactive and independent of each other, jointly influence the condition of bone mass. The combined application of the two-point Dixon water-fat separation technology and micro-CT, on the one hand, could three-dimensionally, accurately and intuitively investigate the bone morphology and parameters, on the other hand, could measure the bone structure parameters of OP trabecular and cortical bone. The current methodology provides more accurate qualitative and quantitative data in OP process, which can fully and accurately evaluate related biological characteristics, thus sheding light on in-depth basic and applied OP research.

\section{Acknowledgements}

Not applicable.

\section{Funding}

This work was supported by the Suzhou Health Bureau Special Program (KJXW2013010) and the Application Fundamental Research Program of Suzhou City (SYS201459).

\section{Availability of data and materials}

All data generated or analyzed during this study are included in this published article.

\section{Authors' contributions}

MZ and XW designed the study, GH and MZ performed the experiments, JX, SH and DG established the animal models, WZ and QW collected the data, $\mathrm{MZ}$ and $\mathrm{CH}$ analyzed the data, 
MZ and XW prepared the manuscript. All authors read and approved the final study.

\section{Ethics approval and consent to participate}

This study was approved by the Animal Ethics Committee of Soochow University Animal Center (Suzhou, China).

\section{Patient consent for publication}

Not applicable.

\section{Competing interests}

The authors declare that they have no competing interests.

\section{References}

1. Kageyama G: The diagnosis and treatment of osteoporosis. Rinsho Byori 63: 570-579, 2015 (In Japanese).

2. Siris ES, Miller PD, Barrett-Connor E, Faulkner KG, Wehren LE, Abbott TA, Berger ML, Santora AC and Sherwood LM: Identification and fracture outcomes of undiagnosed low bone mineral density in postmenopausal women: Results from the National Osteoporosis Risk Assessment. JAMA 286: 2815-2822, 2001.

3. Shen W, Chen J, Gantz M, Punyanitya M, Heymsfield SB, Gallagher D, Albu J, Engelson E, Kotler D, Pi-Sunyer X, et al: MRI-measured pelvic bone marrow adipose tissue is inversely related to DXA-measured bone mineral in younger and older adults. Eur J Clin Nutr 66: 983-988, 2012.

4. Li GW, Tang GY, Liu Y, Tang RB, Peng YF and Li W: MR spectroscopy and micro-CT in evaluation of osteoporosis model in rabbits: Comparison with histopathology. Eur Radiol 22: 923-929, 2012

5. Li G, Xu Z, Chen Y, Chang S, Calimente H, Hu J and Wu D: Longitudinal assessment of marrow fat content using three-point Dixon technique in osteoporotic rabbits. Menopause 23: $1339-1344,2016$.

6. Bouxsein ML and Seeman E: Quantifying the material and structural determinants of bone strength. Best Pract Res Clin Rheumatol 23: 741-753, 2009.

7. Liu SP, Liao EY, Chen J, Yang SM, Li JW, Sheng ZF, Mo H, Wu XP, Yao L and Dai RC: Effects of methylprednisolone on bone mineral density and microarchitecture of trabecular bones in rats with administration time and assessed by micro-computed tomography. Acta Radiol 50: 93-100, 2009.
8. Zhu CT, Li T, Zhang P, Zou M, Guo Q and Qu XW: Beneficial effects of low-level laser irradiation on senile osteoporosis in rats. Eur Rev Med Pharmacol Sci 21: 5230-5238, 2017.

9. Dai QG, Zhang P, Wu YQ, Ma XH, Pang J, Jiang LY and Fang B: Ovariectomy induces osteoporosis in the maxillary alveolar bone: An in vivo micro-CT and histomorphometric analysis in rats. Oral Dis 20: 514-520, 2014.

10. Gatti V, Azoulay EM and Fritton SP: Microstructural changes associated with osteoporosis negatively affect loading-induced fluid flow around osteocytes in cortical bone. J Biomech 66: 127-136, 2018.

11. Minematsu A, Hanaoka T, Takeshita D, Takada Y, Okuda S, Imagita $\mathrm{H}$ and Sakata $\mathrm{S}$ : Long-term wheel-running can prevent deterioration of bone properties in diabetes mellitus model rats. J Musculoskelet Neuronal Interact 17: 433-443, 2017.

12. Di Iorgi N, Rosol M, Mittelman SD and Gilsanz V: Reciprocal relation between marrow adiposity and the amount of bone in the axial and appendicular skeleton of young adults. J Clin Endocrinol Metab 93: 2281-2286, 2008.

13. Shen W, Chen J, Punyanitya M, Shapses S, Heshka S and Heymsfield SB: MRI-measured bone marrow adipose tissue is inversely related to DXA-measured bone mineral in Caucasian women. Osteoporos Int 18: 641-647, 2007.

14. Rahman S, Lu Y, Czernik PJ, Rosen CJ, Enerback S and Lecka-Czernik B: Inducible brown adipose tissue, or beige fat, is anabolic for the skeleton. Endocrinology 154: 2687-2701, 2013.

15. Fanucci E, Manenti G, Masala S, Laviani F, Di Costanzo G, Ludovici A, Cozzolino V, Floris R and Simonetti G: Multiparameter characterisation of vertebral osteoporosis with 3-T MR. Radiol Med (Torino) 112: 208-223, 2007.

16. Hatipoglu HG, Selvi A, Ciliz D and Yuksel E: Quantitative and diffusion MR imaging as a new method to assess osteoporosis. AJNR Am J Neuroradiol 28: 1934-1937, 2007.

17. Hardouin P, Pansini V and Cortet B: Bone marrow fat. Joint Bone Spine 81: 313-319, 2014.

18. Tewari D, Khan MP, Sagar N, China SP, Singh AK, Kheruka SC, Barai S, Tewari MC, Nagar GK, Vishwakarma AL, et al: Ovariectomized rats with established osteopenia have diminished mesenchymal stem cells in the bone marrow and impaired homing, osteoinduction and bone regeneration at the fracture site. Stem Cell Rev 11: 309-321, 2015.

19. Ocarino NM, Boeloni JN, Jorgetti V, Gomes DA, Goes AM and Serakides R: Intra-bone marrow injection of mesenchymal stem cells improves the femur bone mass of osteoporotic female rats. Connect Tissue Res 51: 426-433, 2010.

20. Veronesi F, Torricelli P, Borsari V, Tschon M, Rimondini L and Fini M: Mesenchymal stem cells in the aging and osteoporotic population. Crit Rev Eukaryot Gene Expr 21: 363-377, 2011.

This work is licensed under a Creative Commons Attribution-NonCommercial-NoDerivatives 4.0 International (CC BY-NC-ND 4.0) License. 